\title{
A Rarely Seen Hyperflexion Deformity of the Distal İnterphalangeal Joints as a Consequence of Partially Lacerated Superficial Flexor Tendons in the Palmar Region
}

\author{
${ }^{1}$ Atacan Emre Koçman, ${ }^{2}$ Cüneyd Günay, ${ }^{1}$ Aydan Ayşe Köse, ${ }^{1}$ Cengiz Çetin \\ ${ }^{1}$ Department of Plastic and Reconstructive Surgery, Faculty of Medicine, Eskisehir Osmangazi \\ University, Meselik, 26480, Eskisehir, Turkey \\ ${ }^{2}$ Department of Orthopaedics and Traumatology, Faculty of Medicine, Eskisehir Osmangazi \\ University, Meselik, 26480, Eskisehir, Turkey \\ e-posta: cungunay@hotmail.com
}

\begin{abstract}
We present a 35-year-old female patient with an unusual clinical presentation of partially lacerated superficial flexor tendons of the right hand. Although the superficial tendons were partially lacerated, the distal interphalangeal joints of the third and fourth finger were positioned in hyperflexed condition. This rarely seen examination findings and possible mechanisms were discussed in this study.
\end{abstract}

KEY WORDS: Flexor tendon examination, injury, hand injuries

ÖZET: Sağ elinde yüzeyel fleksör tendonlarının kısmi yırtığı olan 35 yaşındaki kadın hastanın nadir bir klinik tablosunu sunduk. Yüzeyel fleksör tendonların kısmi yırtığı olmasına rağmen, üçüncü ve dördüncü parmak distal interfalangeal eklemler hiperfleksiyon pozisyonunda konumlanmıştır. Bu nadir görülen fizik muayene bulgusu ve olası mekanizmalar bu çalışmada tartışılmıştır.

ANAHTAR KELİMELER: Fleksör tendon muayenesi; yaralanma; el yaralanmaları

\section{Introduction}

Flexor tendon lacerations are more common injuries in hand surgery. Flexor motion of the interphalangeal joint is affected due to lacerations. Deep tendon injuries result in loss of distal interphalangeal (DIP) joint motion, however superficial tendon injuries result in loss of proximal interphalangeal (PIP) joint motion $(1,2)$. When the normal flexion cascade of fingers are disrupted, affected fingers are seen in extension position (1). If the patient was not examined carefully, the superficial tendon injuries can be missed because of active deep tendon movements. Previously, the diagnosing methods of superficial tendon lacerations were reported in the literature(1-4). However, no detailed reports were found about the diagnosis of partially lacerated superficial flexor tendons. Bhatti stated that, all deeplacerations in the hand are considered to be a tendon injury until otherwise proven (1). Here, we present a paradoxical sign of partially lacerated superficial tendons in the palmar region.

\section{Case Report}

A 35-year-old female patient was admitted to the emergency department of our hospital with a deep laceration in the palmar region of the right hand. On physical examination, deep and superficial tendon movements of the third and fourth fingers were observed. When the patient was asked to open her fingers, it was noted that she was not able to open the interphalangeal joints of third and fourth fingers and had pain during this 
examination. While the second and fifth fingers were rest in normal condition, the affected fingers were seen in the hyperflexion position (Figure 1).

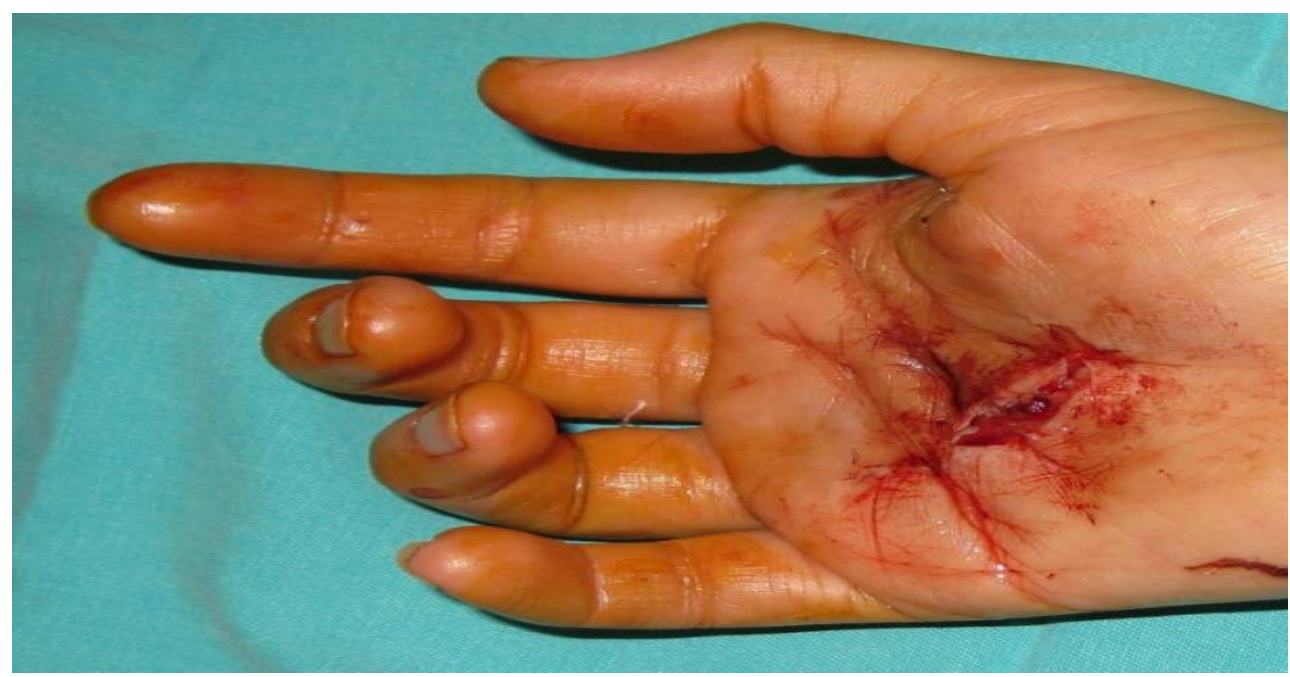

Figure 1. DIP joints of the third and fourth fingers were in flexed position. The second and fifth fingers were in rest position. Also approximately $2 \mathrm{~cm}$ deep skin injury was observed in the palmar region of the right hand.

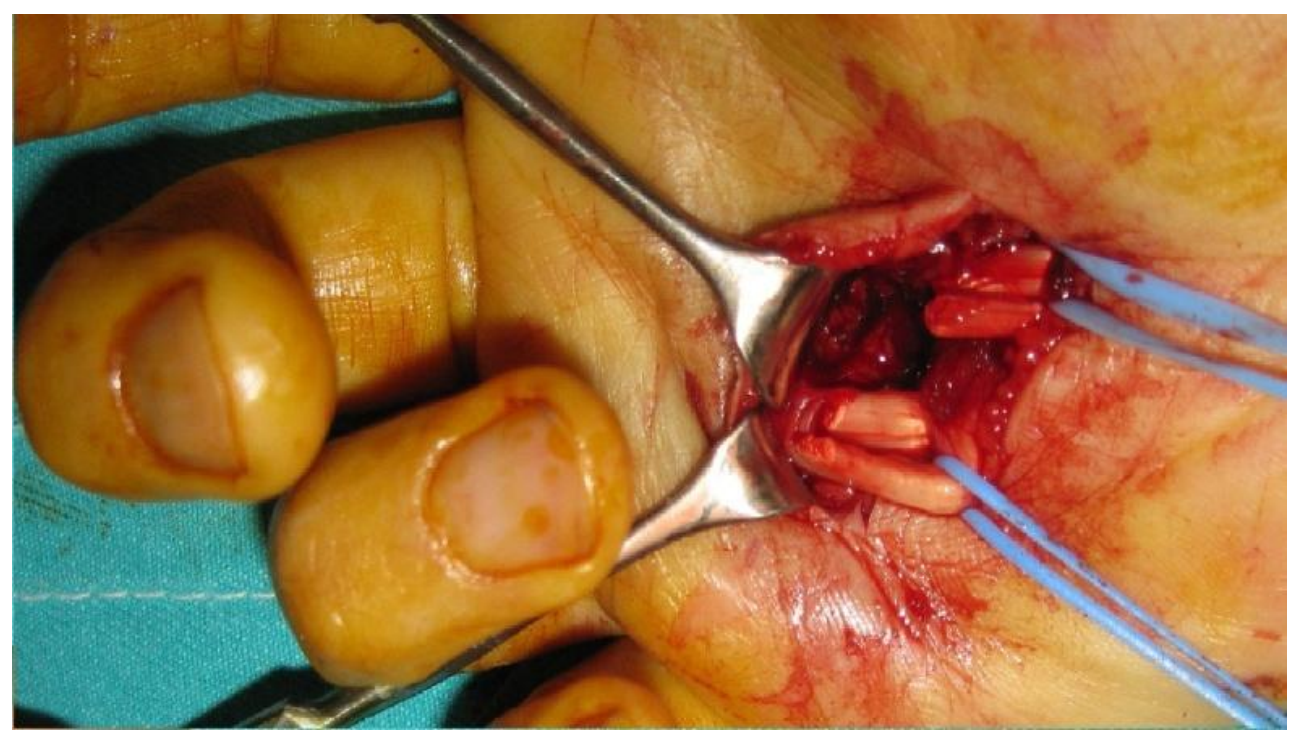

Figure 2. The partially lacerated superficial tendons are shown in the picture.

Exploration of the wound was performed under general anaesthesia. Superficial flexor tendons of the third and fourth fingers were observed to be partially $(70 \%)$ lacerated (Figure 2). Also deep flexors of the affected fingers were found to be minimally (10\%) lacerated, maybe due to this reason, no functional loss was observed. The mechanism of this condition can be explained by the entrapment of the injured superficial flexor tendons at the A1 pulley during the extension movement. This prevents the further excursion of the deep flexor tendons at the same time, and the affected fingers were arrested in hyperflexed position. The tendons were repaired by non-absorbable sutures. Excursion of both 
deep and superficial tendons through A1 pulley were restored and normal flexor cascade of the hand was gained. The patient was followed-up at 3 months interval for 1 year. At the latest follow-up (16 months from the initial diagnosis), she had no problem and was able to move her fingers easily.

\section{Discussion}

The examination of deep and superficial tendons of each finger should be evaluated separately and carefully. If the deep flexor tendons are intact, movement of both DIP and PIP joints, may mask the lacerated superficial tendon. Therefore, several methods were suggested for superficial flexor tendon examination. As a rule to test the flexor tendons, the patient is asked to flex the finger at the PIP joint while the adjacent fingers are held in extension position to neutralize the deep flexors (2). This maneuver reveals whether superficial flexor tendon is intact or not. As mentioned above, the disruption of the flexor cascade of the affected fingers in extended position was also determined on inspection (1). Besides the classical examination, two hyperextension maneuvers were also described previously for testing superficial tendon motion $(3,4)$. Doğan et al. reported that, lacerated superficial flexor tendon, couldn't provide hyperextension of the DIP joint, to show up the pinch position (3). The maneuver, which is described by Mishra, pressing the pulps of all the fingertips together against the proximal part of the palmar region, results flexion the DIP joints, with the absence of the superficial flexor tendon (4). However there is no diagnostic sign documented before for partial lacerations of the superficial flexor tendons. Sasaki et al. reported two cases, with full flexion of the PIP joint caused by an intact short vinculum, after complete laceration of both superficial and deep flexor tendons (5).

The partial lacerations of the flexor tendons should be evaluated, with special attention to prevent spontaneous rupture and adhesion formation. Paradoxical hyperflexion of the fingers was determined in our patient, and this examination finding led us to diagnose the partial lacerations of superficial flexor tendons. In this case, during movement of the tendons on the palmar region, partially lacerated thin and flat superficial tendons cause fan shaped widening and entrapment of the tendons at the A1 pulley. Hence, DIP and PIP joints of the affected fingers were arrested in hyperflexed position, compared to intact ones. This novel clinical observation showed that, paradoxical hyperflexion may be a sign of the entrapment of the partially lacerated superficial flexor tendons. Partial tendon lacerations and this unique examination finding should be kept in mind to regain the normal hand function.

\section{REFERENCES}

1. Bhatti, A.Z. (2006). Identifying tendon injury on induction. Plast Reconstr Surg.117:1062.

2. Lehfeldt, M. Ray, E. Sherman, R. (2008). MOC-PS(SM) CME article: treatment of flexor tendon laceration. Plast Reconstr Surg. 121:1-12.

3. Dogan, T. Celebiler, O. Gürünlüoğlu, R. Bayramiçli, M. Numanoğlu, A. (2000). A new test for superficialis flexor tendon function. Ann Plast Surg. 45:93-6.
4. Mishra, S. (2006). A new test for demonstrating the action of flexor digitorum superficialis (FDS) tendon. $J$ Plast Reconstr Aesthet Surg. 59:1342-4.

5. Sasaki, Y. Nomura, S. (1987). An unusual role of the vinculum after complete laceration of the flexor tendons. J Hand Surg Br. 12:105-8. 